\title{
Study on the Development Trend of Hotel management under
}

\author{
Information Age \\ Siqing Tian ${ }^{1}$ \\ ${ }^{1}$ Chongqing University of Science and Technology \\ 346591653@163.com
}

KEYWORDS: Hotel; Development Trend; Information Age

\begin{abstract}
With the development of global economic integration, China's hotel market competition has become increasingly fierce, the hotel business risk is also growing. In order to improve the competitive advantage of the hotel, the hotel has become a recognized group development direction. However, after several years of exploration and practice, the process of China's hotel industry group is not ideal. The author of Chinese hotel group problem-depth theoretical study, combined with the hotel industry for many years of hands-on and insights, from the need to analyze the development of the Chinese hotel group, study market barriers China Hotel Development Group, China Hotel Group conditions for the development of the analysis and the development path of China hotel Group is dependent on other aspects of Chinese hotel group conducted a study and discussion.
\end{abstract}

\section{Introduction}

Recalling the past three years, the relationship between supply and demand and the conversion of these two elements of the mobile Internet boom has led to the entire Chinese hotel industry has undergone great division, major changes and reorganization of a major reorganization. From the initial Ctrip, eLong, where to go on-line booking system, now appear more to go, ah, donkey mother, public comment and other electronic marketing websites, OTA rely on "Internet + " and "mobile Internet terminal", fully take advantage of network media, great to meet the needs of many young people, but also broadens the hotel's marketing networks and channels. The hotel industry has emerged of widespread losses for several years, losses in 2014 is to reach a peak, but at the same time there have been many prominent personality traits "new format", their development showing a thriving scene. Trend rainbow night so polarized, it is bound to arouse Thinking entire industry.

\section{Hotel Management under Information Age}

Information technology in the enterprise organization widely increased complexity and uncertainty of the external environment. With the acceleration of the process of economic globalization, especially fast, accurate global e-commerce and travel booking network makes the hotel management based on a broader, more efficient, and therefore more intense competition basis. The concept of time and space enterprises are facing competition has undergone a fundamental change in the essence of the enterprise competition has shifted from time and competitive information products market. Openness of the Internet, multimedia and international tourist hotel 
makes business scope expanded to global e-commerce to expand the area of competition in the hotel industry, to enable enterprises to expand the competition from conventional advertising competition, promotions, product design and other fields of the intangible virtual room for competition. Its biggest feature is: The seller or service uses the Internet shopping guide, consumer buyer grasp the initiative. It forms of evolution, market competition heritage bidding auction. The traditional market-oriented marketing model into a network of customer-oriented mode, thus exacerbating the fierce market competition and deepen. As strategists as highlighted in a high turbulence intensity environment, companies must reach out into the market, the establishment of weak signal amplification "early warning system." Before the advent of no opportunity, in accordance with the trend shown, arranged on organizational resources, as prepared, when the time comes, a sign appeared on the mobilization of organizational resources to capture the opportunity to seek more than one step ahead of competitors. Currently, information has become an important organization open input and output. Enterprises of input and output information collection, analysis and processing performance, determine the success or failure of organizational decision making.

Complex environment requires companies to be more flexible organization. IT organizations can enhance the sensitivity of the reaction to the external environment, as well as the ability to communicate between the various departments within the organization and coordination by improving adaptability and responsiveness organizations. In the traditional system of hotel organization, structured, too many intermediate level, through a strict division of labor, forming a hierarchical pyramid structure of longitudinal, decision-making information from the top of the pyramid is transmitted to the longitudinal layer by layer along the bottom. Internet age of information technology functions of the division of the organizational structure will enable the hotel to the integration, the direction of comprehensive development, and the formation of customer-centric, customer-oriented organizational structure of the new system. Issued and not get its information management needs through an intermediate layer, thereby flattening the organizational structure of the pyramid, forming a flat organizational structure model. Its information transmission is all-round, three-dimensional, any department can be timely and easily send and receive information. Hotel executives can understand the lower levels through the network, to grasp the dynamic, and frontline employees can demand the latest information, services timely to reflect upward. Moreover, the network provides for the lack of communication in the past those business people all departments quick and easy way to communicate, so that more can be coordinated to work effectively between departments. Timeliness hotel marketing strategy, flexibility increases.

Extensive use of information technology makes the company's internal management more open, democratic, and used for many years the traditional hotel management mode will have a strong impact. Real-time characteristics of the network asked the hotel management more pragmatic and efficient. Information technology is no longer the company's resources to become part of the corporate environment, an impact on the organizational structure of an argument. Meanwhile, the use of information technology is also in the hotel management put forward higher requirements, not only requires managers to master the scientific management ideas and management methods, but also the use of advanced means of dealing with the increasing complexity of daily internal and external information correct and timely information on the tourist market to react, to make the right business decisions. IT organizations require both enhanced organic, organic organization also improved technical assurance. Enhance information capabilities, managers can make further authorization at all levels of governance, thereby increasing the magnitude of the impact of management, reducing layers of management, enhance horizontal communication within the 
organization and communication with the external environment. The hotel's daily operations, most front-line staff in contact with customers, to understand the most, and most clearly the advantages and disadvantages of hotel products and services, their impact on the quality and efficiency of the largest hotels. Many hotels frontline employees are encouraged to participate in improving the quality, the greater decentralization to employees in influential daily work efficiency and quality of service, allowing employees more involved in decision-making. On the one hand there is a higher staff motivation and sense of responsibility, on the other hand the hotel more quickly to changes in demand to make the right response. The use of modern information technology to build a highly efficient in the original hotel management system, interactive, real-time internal information management system, so that the original structure break down departmental boundaries, using intersectoral groups, decision-making power into the most basic level. Thus the entire hotel service process, we can design workflows to customer-centric. In this process, employees can understand the whole service process, to understand how their decisions affect the overall performance of the hotel. In the future, with constantly updated information technology and the widespread application in the hotels, hotel management is an important tendency is to establish a strategic partnership between the hotel staff and management.

At present, the development of tourism e-commerce applications will once again push the hotel, information technology, network construction, from customer management, marketing, organizational structure and other aspects of computer-aided decision-making, the traditional hotel management model for change updates, comprehensive improve the competitiveness of enterprises. Under the new situation, the hotel will present organizational structure flat, flexible features. Information technology, networking, knowledge-based features more prominent. Learning organization, network organization will become the main form of future hotel. Prevailing variety of management thinking, such as business process reengineering, enterprise, learning organization ideas are with the emergence and development of modern computer information network linked.

\section{The Creation Trend of Hotel Management}

\section{A. Hotels Organizational Innovation}

China's hotel industry in a profound impact on scientific management movement, almost all hotels have formed a hierarchical pyramid organizational system, from the board, general manager, department manager, the supervisor, foreman, waiter, more and more hierarchical levels , processing and transmission of information to go through a number of areas, resulting in the entire organization to reflect changes in the external environment of slow, at a disadvantage in the fierce market competition. Hotel industry a "reengineering" the voice getting higher and higher, and great advances in information processing technology, and breakthrough management shackles for the hotel industry to provide material and technical prerequisites. Vigorously flat organizational structure becomes inevitable.

With the advent of the era of knowledge economy, information technology has become indispensable to modern hotel management tools and techniques, the hotel in the shortest time understanding of customer and market conditions, and therefore should be taken as flexible management, shift from the traditional rigid management dynamic management, problem solving in dynamic, and the flexibility to choose management methods, methods vary inspire employees to effectively implement dynamic management. 


\section{B. The Hotel Marketing Innovation}

Marketing innovation is the first concept of innovation in recent years, there have been some new marketing concept changes, the hotel must adapt to this change, based on the original marketing concepts on establishing the following new concepts: first, the customer satisfaction marketing concept. Customer satisfaction is the key to win the market long-term value creation, to make customer satisfaction, we must strengthen the implementation of the core business processes or improve the hotel, especially for the customer service process management. Second, the concept of coopetition. Acceleration of global economic integration process, exacerbating the intensity of competition in the market, the main competition by a single collective enterprise and it is turning to business. So the hotel only to closely monitor changes in consumer demand, but also to always pay attention to competitors' marketing strategy, in terms of services, quality of service, and human resources-round competition, highlighting features, and focus on cooperation in the competition, to be good to his opponent Learn. Third, the concept of green marketing. At present, the green revolution sweeping the globe, environmental protection and sustainable development has become the world's most concerned about the issue of consumption "green" trend is increasingly evident, green products and services more competitive, to bring good returns.

\section{Conclusion}

Today, information has become the lifeblood of tourism. It has become the core of tourism. A set of system being permeates the entire tourism industry to go. No one can escape its influence. "The hotel has been under siege network information Who among the early recognition and application of the latest achievements of the information revolution, who will be in a highly competitive market, greater market space, profit opportunities, having more stronger competition Advantage.

\section{REFERENCE:}

[1] Odysseas Pavlatos, Ioannis Paggios Cost accounting in greek hotel enterprises. An empirical approach [J]. tourismos.2007 (2): 39-59.

[2] Athanasios Vazakidis, Ioannis Karagiannis. Activity-based management and traditional costing in tourist enterprises (a hotel implementation model) [J]. Springer-Verlag.2009.

[3] Liang Hong. Management accounting assumptions of [J]. Sichuan accounting .2000 (2).

[4] Zhang Gang. Costing and Traditional Costing compared with the use of [J]. Accounting Monthly [J] .2001 (6). 